\title{
Robust moisture reference year methodology for hygrothermal simulations
}

\author{
Xiaohai Zhou ${ }^{1,2}$, Dominique Derome ${ }^{2}$ and Jan Carmeliet ${ }^{1,2}$ \\ ${ }^{1}$ Chair of Building Physics, ETH Zürich, Zürich, Switzerland \\ ${ }^{2}$ Laboratory of Multiscale Studies in Building Physics, Empa, Dübendorf, Switzerland
}

\begin{abstract}
Hygrothermal models allow designers to evaluate the hygrothermal performance of building envelopes. A key question in hygrothermal modeling however remains in the proper selection of representative exterior moisture conditions, i.e. a moisture reference year. A Climatic Index combining wind-driven rain load and potential evaporation is developed allowing considering the effect of climatic variability on the performance of the building envelope. The proposed Climatic Index combines thus both the wetting load and evaporation potential. This index is suitable for the evaluation of the level of moisture damage risk of wall assemblies where typical moisture problems are mainly caused by rainwater uptake or ingress.

The Climatic Index is determined for four cities in Switzerland. The hygrothermal performance of the assemblies is simulated and evaluated using a hygrothermal indicator, called the RHT Index. A clear correlation between Climatic Index and RHT Index is found. However, the moisture reference year selected based solely on a $10 \%$ level criterion of the Climatic Index may not correspond to the year with the most significant moisture damage risk. Therefore, a new procedure is proposed which combines a first selection of three years around the $10 \%$ level criterion, followed by a careful comparison of these years based on hygrothermal simulations and selection of the year with the largest RHT Index as moisture reference year. The combination of Climatic Index and RHT Index from hygrothermal simulations allows for the selection of moisture reference years that are around the $10 \%$ level, but excluding the ambiguity.
\end{abstract}

This document is the accepted manuscript version of the following article: Zhou, X., Derome, D., \& Carmeliet, J. (2016). Robust moisture reference year methodology for hygrothermal simulations. Building and Environment, 110, 23-35. http://doi.org/10.1016/j.buildenv. 2016.09.021

This manuscript version is made available under the CC-BY-NC-ND 4.01 icense http://creativecommons.org/1icenses/by-nc-nd/4.0/ 


\section{Introduction}

Good hygrothermal performance of building envelopes is crucial as moisture damage is one of the main causes of building envelope deterioration. Excessive moisture accumulation in building envelopes may lead to structural damage, mold growth, decrease of thermal resistance of building materials and degradation of indoor air quality. An effective moisture control in the building envelope ensures building long-term service life [1]. It is essential for designers and builders to understand the moisture conditions of a climate region to assess correctly building envelope durability. Traditional steady-state methods such as Glaser [2] and dew point methods [3] cannot predict the long-term moisture response of a wall assembly, in particular when rainwater is taken up by the walls. Numerical hygrothermal models, simulating the coupled transport of heat and moisture over varying environmental conditions, have the ability to provide the data necessary to assess long-term heat and moisture performance of wall assemblies and predict the risk of moisture damage. But hygrothermal models require the selection of representative climatic data including rainfall, air temperature, relative humidity, solar radiation, longwave radiation, wind speed and velocity as input, on yearly basis [4]. Representative climatic data should reflect the climatic variability subjected to the building envelope under consideration and provide the required level of safety with regard to moisture problems [5]. A common approach is to determine a reference year from available long-term climatic data.

Compared to energy reference years that use mean values of climate data for the locations under consideration [6-8], a moisture reference year should represent a climate that allows a correct evaluation of the moisture stress on the building envelope. Moisture problems are often caused by a combination of several extreme weather conditions. A $10 \%$ level criterion is often suggested to select moisture reference years. The choice of a 10\% damage risk is justifiable, since this choice refers to a return period of 10 years, which for hygrothermal problems is appropriate, allowing the moisture accumulated during a bad year to dry out in the following years preventing long term deterioration [9]. Different methods have been used to define moisture reference years. Ali Mohamed and Hens [10] suggested that the critical moisture reference year (MRY) could be related with the annual mean outdoor temperature. By comparison, Geving [11] suggested that the MRY could be related to the annual mean outdoor relative humidity. Hagentoft and Harderup [12] presented that the MRY could be related to a $\Pi$ factor, which describes the drying potential of a wall by defining the difference between the absolute humidity by volume at saturation and the actual absolute humidity by volume of the outdoor air. Kalamees and Vinha [5] used a method similar to a $\Pi$ factor to select the MRY for evaluating the risk of water vapor condensation. In the above methods, the selection of the MRY is either based on a wetting potential or drying potential, not on both.

Cornick et al. [13] formulated a Moisture Index (MI) method to select MRY, which comprises both wetting and drying indices. The wetting index (WI) is based on the mean annual total horizontal rainfall or annual wind-driven rain load. The drying index (DI) represents the annual evaporation potential. It is defined as the sum of the hourly difference between the saturation vapor ratio and actual vapor ratio of the ambient air. As the wetting index and drying index have different units, they are normalized. The normalization scheme is given as follows:

$$
I_{\text {normalized }}=\left(\mathrm{I}-\mathrm{I}_{\min }\right) /\left(\mathrm{I}_{\max }-\mathrm{I}_{\min }\right)
$$

where I represents the annual wetting index or drying index. $I_{\min }$ and $I_{\max }$ represent respectively the minimum and maximum annual wetting or drying index over the considered years. 
The Moisture Index is calculated based on the normalized wetting and drying indices using the following equation:

$$
M I=\sqrt{W I_{\text {normalized }}^{2}+\left(1-D I_{\text {normalized }}\right)^{2}}
$$

The advantage of the Moisture Index method is that it reflects actual environmental conditions as subjected to a wall during wetting or drying. However, there are several drawbacks with this method. Firstly, the drying potential is actually primarily influenced by the difference between the saturation vapor ratio at the wall surface and the water vapor ratio in the air, rather than the difference between saturation vapor ratio of the surrounding air and actual vapor ratio in the surrounding air as used in the MI method [14]. Secondly, wetting and drying potentials are very different physical quantities, showing different units. Finally, meteorological factors such as wind speed, short-wave solar radiation and long-wave radiation are not taken into account in the calculation of the drying index.

Therefore, an index with a more accurate representation of the drying process at the wall envelope surface is required. The drying of moisture from building envelopes occurs mainly through evaporation. The evaporation process is affected by temperature, air humidity, wind speed, water availability and net radiation. Coming from soil science, the concept of potential evaporation is a measure of the ability of the atmosphere to remove water from the surface through the processes of evaporation [15]. It is defined as the evaporation rate that occurs when a sufficient water source is available. Compared to actual evaporation, which is the quantity of water that is actually removed from a surface by evaporation, potential evaporation is independent of material type and structure and only depends on climatic conditions.

Moisture reference years can be selected based on the evaluation of different climatic variables. It is noted that the relation between the criteria for selecting a moisture reference year and the criteria for evaluating moisture performance is complex. Salonvaara et al. [16] stated that none of the existing methods for selecting a critical moisture reference year for hygrothemal simulations is satisfactory in terms of providing a known level of moisture performance using the RHT Index [17] to select moisture reference years that are among the most severe for the simulated structures.

The objective of this paper is to develop a methodology for the proper selection of moisture reference years required for hygrothermal performance studies. We propose the combined use of a Climatic Index for evaluating the climatic conditions and the RHT Index which allows the evaluation of the hygrothermal behavior. The Climatic Index comprises wetting and drying components, where the wetting component is based on the annual wind-driven rain load and the drying component on the annual potential evaporation. Hygrothermal simulations for four regions in Switzerland and for three different masonry wall systems are performed to predict temperature and moisture content distributions in the wall components. The RHT Index has been used to evaluate the hygrothermal performance of the different wall systems. The correlation between the Climatic Index and the RHT Index is evaluated. Moisture reference years are then selected using a combination of Climatic Index and RHT Index.

\section{The Climatic Index approach}


In general, the moisture conditions of building envelopes result from their wetting and drying behavior. A reference year for hygrothermal calculations should consider the critical climatic conditions which allow to evaluate the hygrothermal performance of a building envelope providing a required level of safety in terms of moisture damage. The moisture reference year should be selected by considering both wetting and drying components. Regarding the wetting component, wind-driven rain (WDR) is the largest moisture source that impacts durability of building envelopes. The orientation of the facade strongly affects the amount of wind-driven rain on the facade. Drying results from the evaporation of water from porous building materials to the surrounding air. Potential evaporation is a measure of the ability of the environment to remove water from the building envelope through the process of evaporation at its surface. Both wetting moisture load and evaporation potential are indispensable environmental factors for the evaluation of the hygrothermal behavior of building envelopes.

A Climatic Index can be considered to be a measure of the balance between the wetting and drying components. A simple way to evaluate the moisture stress on a facade is to compare wetting load to drying potential, dividing the annual wind-driven rain load by the annual potential evaporation, as follows,

$$
\text { Climatic Index }=\frac{\text { annual wind driven rain load }}{\text { annual potential evaporation }}
$$

The numerator represents the wetting component while the denominator represents the drying component. Therefore, a higher Climatic Index value represents a higher moisture risk for the building envelope. The Climatic Index should consider the influence of façade orientation, air temperature, air humidity, wind speed and direction as will be described below. Compared to the previously proposed Moisture Index [13], the proposed formulation in this paper does not need a normalization, since both wetting and drying components show the same units.

\subsection{Wind-driven rain load}

Three methods exist for estimating the WDR load on building surfaces: (1) measurements, (2) semiempirical methods, and (3) numerical simulation. Measurement of WDR is costly and case-specific [18]. Although very accurate and despite recent advancements with an Eulerian-Eulerian multiphase approach, the numerical simulation of WDR with CFD is still quite complex and time consuming [19]. Semiempirical methods offer fast and sufficiently accurate ways of calculating WDR. Therefore, a semiempirical method is used in this study, although some drawbacks are mentioned in Kubilay et al. [19]. The wind-driven rain load for different wall orientations is calculated according to ASHRAE Standard 160 Criteria for Moisture Control Design Analysis in Buildings [20], where the WDR intensity $\left(R_{W D R}\right)$ is defined by the following equation:

$$
R_{W D R}=R_{h} \times F_{E} \times F_{D} \times 0.2 \times V_{10} \times \cos \theta
$$

where $R_{h}$ is the horizontal rainfall amount $\left(\mathrm{kg} \mathrm{m}^{-2} \mathrm{~h}^{-1}\right) ; F_{E}$ is the rain exposure factor; $F_{D}$ is the rain deposition factor; $V_{10}$ is the wind speed at $10 \mathrm{~m}$ above ground $\left(\mathrm{ms}^{-1}\right) ; \theta$ is the angle between the wind direction and the normal to the façade (rad). Factor $F_{E}$ depends on the surrounding terrain and the height 
of the building, while Factor $F_{D}$ describes the influence of the building itself. The annual WDR is calculated as the sum of hourly $R_{W D R}$ and the units are $\mathrm{kg} \mathrm{m}^{-2} \mathrm{a}^{-1}$.

\subsection{Potential evaporation}

The concept of potential evaporation is based on the observation that, when an initially saturated porous material is exposed and allowed to dry gradually to the open air, longer increments of time are progressively required to remove equal increments of water [15]. Various empirical approaches have been proposed for the estimation of potential evaporation [21-24]. The Penman equation [22], based on a combination of energy balance and aerodynamic transport considerations, is widely used in the field of agricultural and environmental physics for predicting potential evaporation. The method for determining potential evaporation using the Penman equation is described next.

The energy balance for an evaporating body can be written as:

$$
K+L-I E-V-A=0
$$

where $K$ is the net short-wave radiation $\left(\mathrm{Wm}^{-2}\right), L$ is the net long-wave radiation $\left(\mathrm{Wm}^{-2}\right), I E$ is the latent convective flux associated with the evaporation of vapor $\left(\mathrm{Wm}^{-2}\right), V$ is the sensible convective heat flux to the atmosphere $\left(\mathrm{Wm}^{-2}\right), A$ is the conductive heat flux to the porous material $\left(\mathrm{Wm}^{-2}\right)$.

The sensible heat transfer flux for an evaporating surface is given by:

$$
V=\rho_{a} C_{p} K_{H} \frac{\partial T}{\partial x}
$$

where $\rho_{a}$ is the density of air $\left(\mathrm{kgm}^{-3}\right), C_{p}$ is the specific heat of air $\left(\mathrm{Jkg}^{-1} \mathrm{~K}^{-1}\right), K_{H}$ is the turbulent air diffusivity for heat $\left(\mathrm{m}^{2} \mathrm{~s}^{-1}\right)$, and $\frac{\partial T}{\partial x}$ is the temperature gradient at the surface $\left(\mathrm{Km}^{-1}\right)$.

The evaporation vapor flux is given by:

$$
E=\frac{\rho_{a} \varepsilon}{P_{a}} K_{V} \frac{\partial e}{\partial x}
$$

where $E$ is the evaporation flux $\left(\mathrm{kgm}^{2} \mathrm{~s}^{-1}\right), \varepsilon$ is the water to air molecular weight ratio $(0.622), P_{a}$ is the air pressure $(\mathrm{Pa}), K_{V}$ is the turbulent diffusivity for vapor $\left(\mathrm{m}^{2} \mathrm{~s}^{-1}\right)$, and $\frac{\partial e}{\partial x}$ is the vapor partial pressure gradient at the surface $\left(\mathrm{Pam}^{-1}\right)$.

The transport of vapor and heat by eddy diffusion are in essence controlled by the same physical mechanism. Therefore, when the normalized temperature and humidity gradients are equal in stable 
conditions, the turbulent diffusivities for vapor and heat are equal $\left(K_{H} / K_{V}=1\right)$. The ratio of sensible heat flux to latent heat flux is called the Bowen ratio, $\beta$ :

$$
\beta=\frac{V}{I E}=\frac{\rho_{a} C_{p} K_{H} \frac{\partial T}{\partial x}}{I \times \frac{\rho_{a} \varepsilon}{P_{a}} K_{V} \frac{\partial e}{\partial x}}=\frac{P_{a} C_{p}}{I \varepsilon} \frac{\Delta T}{\Delta e}=\gamma \frac{\Delta T}{\Delta e}=\gamma \frac{T_{s}-T_{a}}{e_{s}-e}
$$

where $I$ is the latent heat of vaporization $\left(\mathrm{Jkg}^{-1}\right), \gamma$ is the psychrometric constant, $\frac{P_{a} C_{p}}{I \varepsilon}\left(\mathrm{PaK}^{-1}\right), T_{s}$ is the temperature of the surface $(\mathrm{K}), T_{a}$ is the temperature of the air $(\mathrm{K}), e_{s}$ is the saturated vapor partial pressure at the temperature of the surface $(\mathrm{Pa})$, and $e$ is the vapor partial pressure in the air $(\mathrm{Pa})$.

Using the Bowen ratio, the energy balance equation can be rewritten as:

$$
K+L-I E-\beta \times I E-A=0
$$

As a result, the latent heat flux can be described with the following equation:

$$
I E=\frac{K+L-A}{1+\beta}
$$

The Dalton equation for evaporation from a saturated surface is [15]:

$$
I E=\left(e_{s}-e\right) f(\mathrm{u})
$$

where $\mathrm{u}$ is the wind speed $\left(\mathrm{ms}^{-1}\right), f(\mathrm{u})$ is the wind function $\left(\mathrm{Wm}^{-2} \mathrm{~Pa}^{-1}\right), e_{s}$ is the saturated vapor partial pressure at the temperature of the surface $(\mathrm{Pa})$, and $e$ is the vapor partial pressure in the air $(\mathrm{Pa})$. The wind function $f(\mathrm{u})$ is often determined empirically and thus may be location specific.

The Bowen ratio can then be reformulated as:

$$
\beta=\gamma \frac{T_{s}-T_{a}}{e_{s}-e}=\gamma\left(\frac{e_{s}-e_{a}}{e_{s}-e}\right) /\left(\frac{e_{s}-e_{a}}{T_{s}-T_{a}}\right)=\frac{\gamma}{\Delta}\left(\frac{e_{s}-e_{a}}{e_{s}-e}\right)=\frac{\gamma}{\Delta}\left(1-\frac{e_{a}-e}{e_{s}-e}\right)
$$

where $e_{a}$ is the saturated partial vapor pressure of the air, $\Delta=\frac{e_{s}-e_{a}}{T_{s}-T_{a}}$ is the slope of the relationship between saturation vapor partial pressure and air temperature. Equation (10) then becomes:

$$
I E=\frac{K+L-A}{1+\beta}=\frac{K+L-A}{1+\frac{\gamma}{\Delta}\left(1-\frac{e_{a}-e}{e_{s}-e}\right)}=\frac{K+L-A}{1+\frac{\gamma}{\Delta}\left(1-\frac{e_{a}-e}{I E / f(\mathrm{u})}\right)}
$$


Moving $I E$ to the left side, the above equation becomes:

$$
I E=\frac{K+L-A+\frac{\gamma}{\Delta} f(\mathrm{u})\left(e_{a}-e\right)}{1+\frac{\gamma}{\Delta}}=\frac{\Delta(K+L-A)+\gamma f(\mathrm{u})\left(e_{a}-e\right)}{\Delta+\gamma}
$$

The evaporation from a saturated surface can also be described with a convective vapor transfer coefficient:

$$
E=h_{m}\left(e_{s}-e\right)
$$

where $h_{m}$ is the convective vapor transfer coefficient $\left(\mathrm{sm}^{-1}\right)$.

Comparing Equations (11) and (15), we get:

$$
I E=I \times E=I \times h_{m}\left(e_{s}-e\right)=\left(e_{s}-e\right) f(\mathrm{u})
$$

Therefore, the relation between the wind function and convective vapor transfer coefficient is:

$$
f(\mathrm{u})=I h_{m}
$$

The Penman equation for predicting the potential evaporation from a vertical surface then becomes:

$$
E=\frac{\Delta \frac{K+L-A}{I}+\gamma h_{m}\left(e_{a}-e\right)}{\Delta+\gamma}=\frac{\Delta}{\Delta+\gamma} \frac{K+L-A}{I}+\frac{\gamma}{\Delta+\gamma} h_{m}\left(e_{a}-e\right)
$$

The Penman equation thus consists of two terms: the radiation term $\left(\frac{\Delta}{\Delta+\gamma} \frac{K+L-A}{I}\right)$ and the turbulence term $\left(\frac{\gamma}{\Delta+\gamma} h_{m}\left(e_{a}-e\right)\right)$. The radiation term is determined mainly by the energy balance at the surface, while the turbulence term is strongly affected by the atmospheric conditions. The annual potential evaporation is calculated as the sum of the daily potential evaporation. In the Penman method, the conduction heat flux on a daily basis is neglected since the net heat conduction flux to ground conduction is often the smallest component of the daily surface energy balance. Much of the energy that enters the porous medium during the day is returned to the atmosphere at night. Consequently, the conduction heat flux can be neglected for calculation of potential evaporation on a daily basis. However, the conduction heat flux on short-term (i.e. hourly or 10 minutes) shows a lot of variation as well during daytime and nighttime, and neglecting the conduction heat flux on short-term on the energy balance can lead to considerable errors. Therefore, following the Penman method, we also neglect the term A (conduction heat flux) and is set it to 0 . 
The conduction heat flux is negligible compared to other heat fluxes on a daily basis as the change in the stored heat in the porous medium is negligible over a single day. Therefore, the term A (conduction heat flux) is set to 0 .

\section{Hygrothermal simulations}

Hygrothermal modeling is used to calculate the temperature and moisture distributions in building envelope assemblies. The governing equations for moisture and heat transport are the same as those in HAMFEM [25], and are solved using the finite element solver COMSOL. The numerical heat and mass transfer model was validated in a HAMSTAD benchmark [26]. In this paper, we consider only 1D heat and mass transport in multilayer envelopes. In order to consider different wall assemblies, three types of masonry wall assembles are selected for hygrothermal modeling (Fig. 1), which are (1) a three brick wythes masonry wall without insulation, (2) an internally-insulated masonry wall and (3) an externallyinsulated masonry wall. The masonry building assemblies consists of the following materials: lime plaster, brick, mortar, aerogel insulation plaster (except for wall 1) and an interior plaster. The material properties of lime plaster are from the WUFI material database [27], the material properties of brick are from Hagentoft et al., (2004) [26], the material properties of aerogel insulation plaster and mortar are from Guizzardi [28] and the material properties of interior plaster are from HAMFEM database. Compared to traditional insulation materials, an aerogel-based insulation plaster has interesting application potential as retrofit solution in the building industry given its higher insulating value [27]. The good thermal insulation performance of the aerogel plaster has the advantage of reducing the insulation layer thickness and thus of yielding smaller loss of space. In addition, the aerogel plaster can be easily applied to fill any gap in an uneven surface and reach a continuous thermal insulation layer. We remark that the aerogel rendering shows moisture buffering effects and is moderately vapor open.

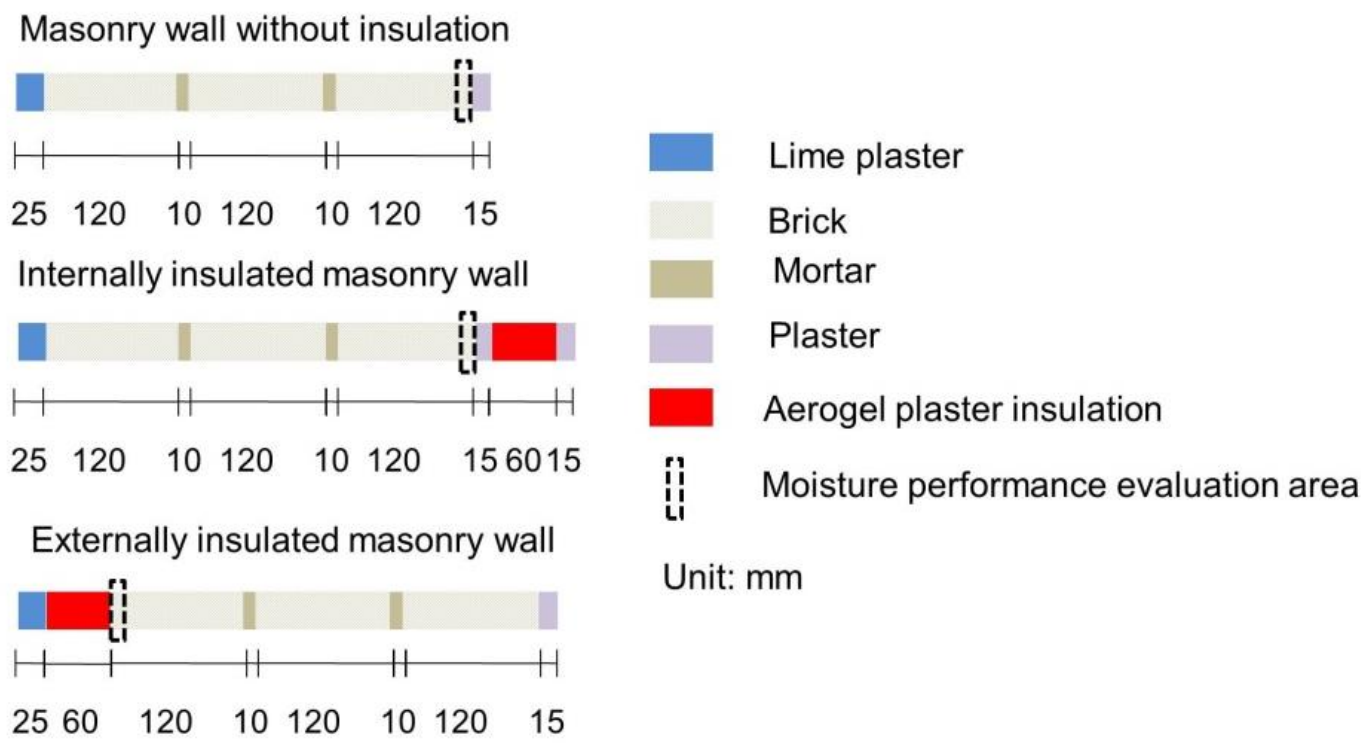

Fig. 1: Schematic representation of 3 masonry wall assemblies

\subsection{Selected locations}


To represent different microclimatic regions in Switzerland, four geographic locations (Fig. 2), i.e. Zurich, Geneva, Lugano and Davos, are selected. Zurich and Geneva are two large cities north of the Alps, Lugano is a city south of the Alps and Davos is an Alpine village, located in the eastern Swiss Alps. The prevailing windflows from westerly directions transport wet air to Switzerland and are responsible for the different precipitation levels in the country. Most areas receive an adequate amount of precipitation throughout the year. The mean annual precipitations in Zurich, Geneva, Lugano and Davos are 1086, 971, 1545 and $1022 \mathrm{~mm}$, respectively. The Alps are acting as a prominent climatic barrier between northern and southern Switzerland. Southern Switzerland, which is mainly influenced by the Mediterranean sea, is characterized by a milder climate than northern Switzerland. The mean annual temperatures in Zurich, Geneva, Lugano and Davos are 8.8, 9.9, 11.9 and $3.9^{\circ} \mathrm{C}$, respectively.

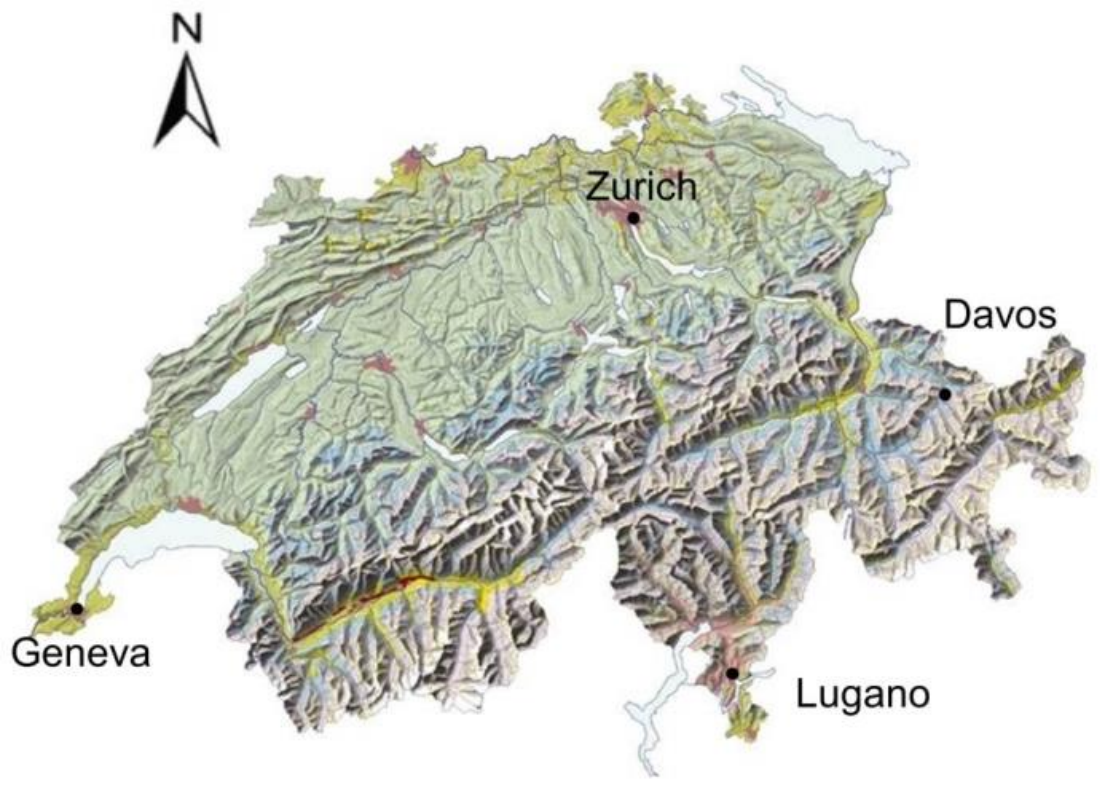

Fig. 2 The chosen four geographic locations in Switzerland (image: swisstop).

\subsection{Meteorological conditions}

30 years of weather data (1981-2010) for each city from MeteoSwiss are used as climatic input data for the hygrothermal modeling. The meteorological data include hourly horizontal rainfall rate, horizontal solar radiation, air temperature and relative humidity, wind speed and direction. A meteorological year beginning in October and ending in September is most reasonable as the moisture conditions within the building envelope during the winter affect the moisture conditions during the summer. For example, the meteorological year 1981 represents the period from 1 October, 1981 to 30 September, 1982. For each city and each wall assembly, 30 different simulations represent each a different meteorological year starting from the same initial conditions were performed. For each year, the meteorological data are repeated for four years and the results of the fourth year, which are found to be independent from the initial condition, are used for analysis. 
The convective vapor transfer coefficient $\left(h_{\mathrm{m}}\right)$ is related to the convective heat transfer by the use of the Lewis analogy $\left(h_{h}\right): h_{\mathrm{m}, i}=h_{h, i} \times 7.7 \times 10^{-9}$. The convective heat transfer coefficient is set to be $4+4 \times V_{v}$ $\mathrm{Wm}^{-2} \mathrm{~K}$ according to the European standard EN15026 [29], where $V_{v}$ is the wind velocity at $10.0 \mathrm{~m}$ height. The short-wave absorptivity and long-wave absorptivity are kept constant at 0.7 and 0.93 , respectively. In the study, the rain exposure factor and rain deposition factor are both assumed to be equal to 1.0. A rain exposure factor of 1.0 indicates medium exposure to rain and a rain deposition factor of 1.0 refers to deposition onto the walls of a building with a flat roof.

As meteorological stations only measure global shortwave radiation on a horizontal surface, the equations extensively explained in Iqbal [30] are used to calculate direct and diffusive radiation on an inclined or vertical surface based on the global short-wave radiation measurement on a horizontal surface.

\subsection{Moisture performance evaluation criteria}

Building materials are subjected to deterioration under the combined effect of temperature and moisture. The results from hygrothermal simulations are analyzed using a hygrothermal response indicator, called the RHT Index [31]. The RHT Index indicates risk of degradation mechanism such as mold growth and cannot be used to evaluate frost damage. The RHT Index can be used to quantify and compare the hygrothermal response of different parts of a wall component. In view of a specific degradation/damage mechanism, relative humidity and temperature at different output time steps are required to obtain the RHT Index. 10-day interval averaged relative humidities, RH $(\%)$, and temperatures, $\mathrm{T}\left({ }^{\circ} \mathrm{C}\right)$, are used for obtaining RHT Index. The RHT Index is defined as:

$$
R H T=\sum\left(R H-R H_{x}\right) \times\left(T-T_{x}\right), \quad \text { for } R H>R H_{x} \text { and } T>T_{x}
$$

where threshold values $R H_{x}=80 \%$ and $T_{x}=5{ }^{\circ} \mathrm{C}$ are used. The degradation mechanism considered here is that of mold occurrence, possible at relative humidity larger than $80 \%$ and temperature larger than $5{ }^{\circ} \mathrm{C}$. For a different degradation mechanism, another index with different threshold value has to be chosen. For example, the thresholds used for metal corrosion are a temperature above $0{ }^{\circ} \mathrm{C}$ and a relative humidity above $80 \%$ [32]. For comparison, decay of wood material occurs when the relative humidity is above $95 \%$ and the temperature above $0{ }^{\circ} \mathrm{C}$ [33]. The RHT Index evaluates the risk for moisture damage using the combined moisture and temperature response of a selected region in the building envelope, called here the evaluation region. For the masonry wall without insulation and for the internally insulated masonry wall, the evaluation region is chosen at the innermost $1 \mathrm{~cm}$ of the third brick (Fig. 1). This region is in contact with the interior finishing, while still being considerably affected by the external climate conditions. For the externally insulated masonry wall, the outermost $1 \mathrm{~cm}$ of the first brick is selected as evaluation region (Fig. 1), as this is the most critical region of the masonry wall in the case with external insulation.

\section{Results}

Hourly meteorological data from MeteoSwiss stations from the year 1981 to 2010 are used to calculate the annual WDR and the potential evaporation. Figs. 3 and 4 show the WDR and potential evaporation roses for the year 1994. The WDR is dependent on the horizontal rainfall intensity, wind speed and wind direction. For Zurich and Geneva, a southwest-facing wall receives the largest amount of WDR. For Lugano, the wall orientation with the largest WDR is northwest. For Davos, due to the influence of 
surrounding topography, a northeast-facing wall receives the largest amount of WDR. Among the four cities, Zurich and Geneva show much larger WDR. For each city, the WDR varies considerably with orientation. For instance, the WDR for a northeastern orientation in Zurich is smaller than $50 \mathrm{mma}^{-1}$ while it is larger than $600 \mathrm{mma}^{-1}$ for the southwestern orientation (Fig. 3). Compared to WDR, the potential evaporation presents smaller variations with orientation. For example, in Zurich, the lowest potential evaporation for the north direction is about $800 \mathrm{mma}^{-1}$, while the largest one is around $1150 \mathrm{mma}^{-1}$ for the south direction. For all the four cities, the south-facing wall has the largest potential evaporation. Due to the effect of solar radiation, Lugano has the largest potential evaporation while Davos has the smallest potential evaporation. In order to select the orientation which gives the most severe moisture problems, the orientation with the largest Climatic Index is selected for hygrothermal simulation. The orientation with the largest Climatic Index is found to be similar for all years for each of the cities. Therefore, the selected wall orientations for further analysis are 240, 240, 330 and 30 degrees from north, for Zurich, Geneva, Lugano and Davos respectively.

$$
\text { Climatic Index }=\frac{\text { annual wind driven rain load }}{\text { annual potential evaporation }}
$$
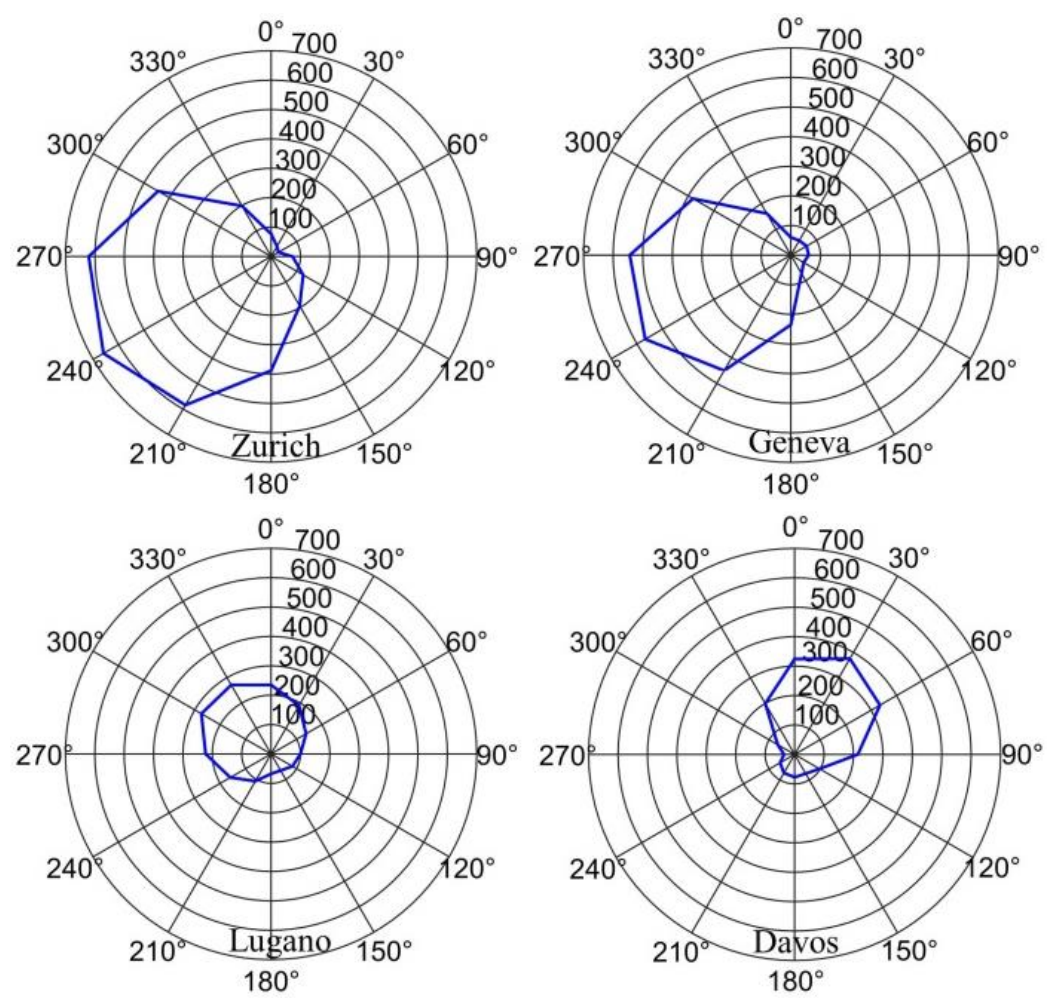

Fig. 3 Wind driven-rain rose for Zurich, Geneva, Lugano and Davos in 1994 (unit: $\mathrm{mm} \mathrm{a}^{-1}$ ). 

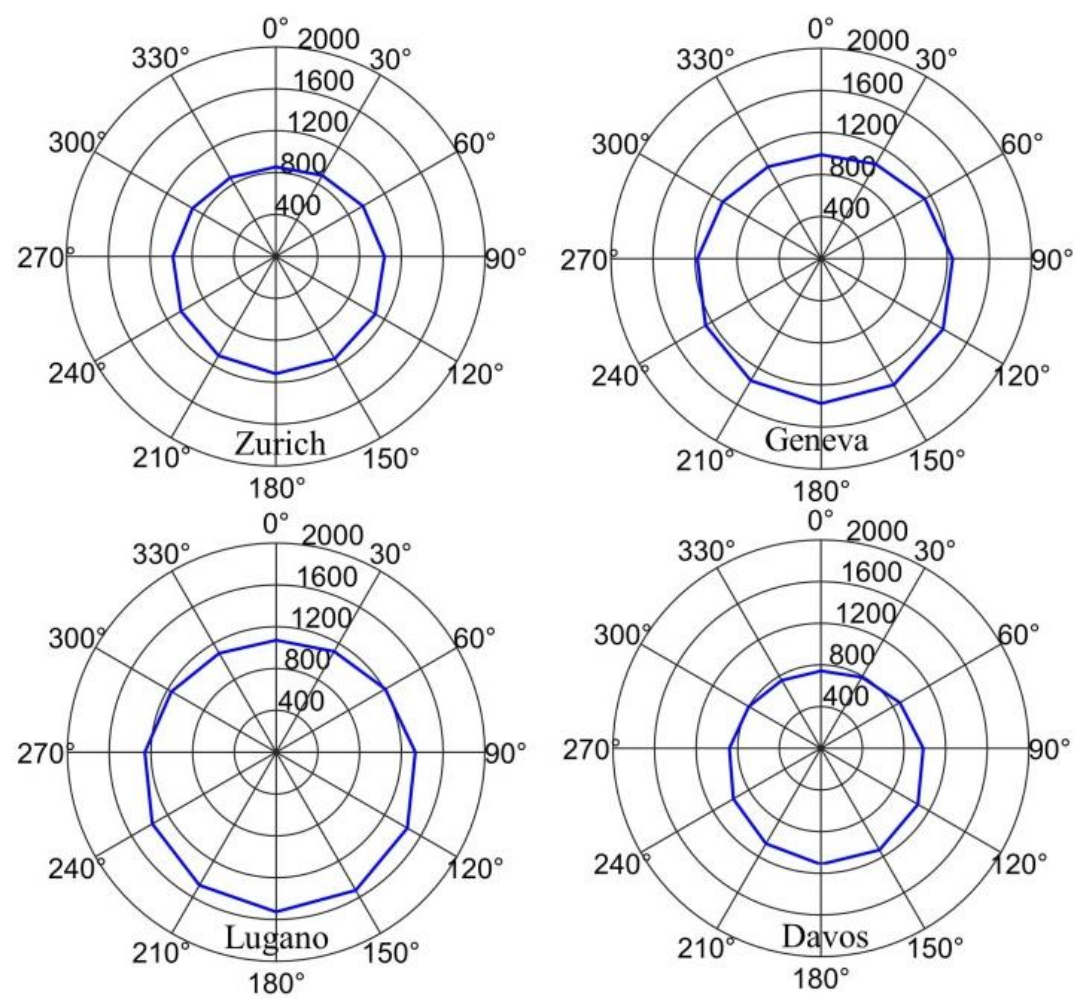

Fig. 4 Potential evaporation rose for Zurich, Geneva, Lugano and Davos in 1994 (unit: $\mathrm{mm} \mathrm{a}^{-1}$ ).

Fig. 5 shows the cumulative distribution functions of WDR, potential evaporation and Climatic Index in Zurich, Geneva, Lugano and Davos from 1981-2010 for the selected orientations. Zurich shows the largest WDR, while Geneva has the largest potential evaporation (Fig. 5 and Table 1). The small potential evaporation at Lugano is due to its northeast-facing wall orientation. The Climatic Indices in Zurich show the largest values, while the Climatic Indices in Lugano are the smallest ones. The Climatic Index values for all 30 years in the four cities are given in Table 2 in order of descending Climatic Index. The largest Climatic Index is 0.630 in the year of 1994 in Zurich, while the smallest index is 0.133 in the year of 2005 in Davos (Table 2). 

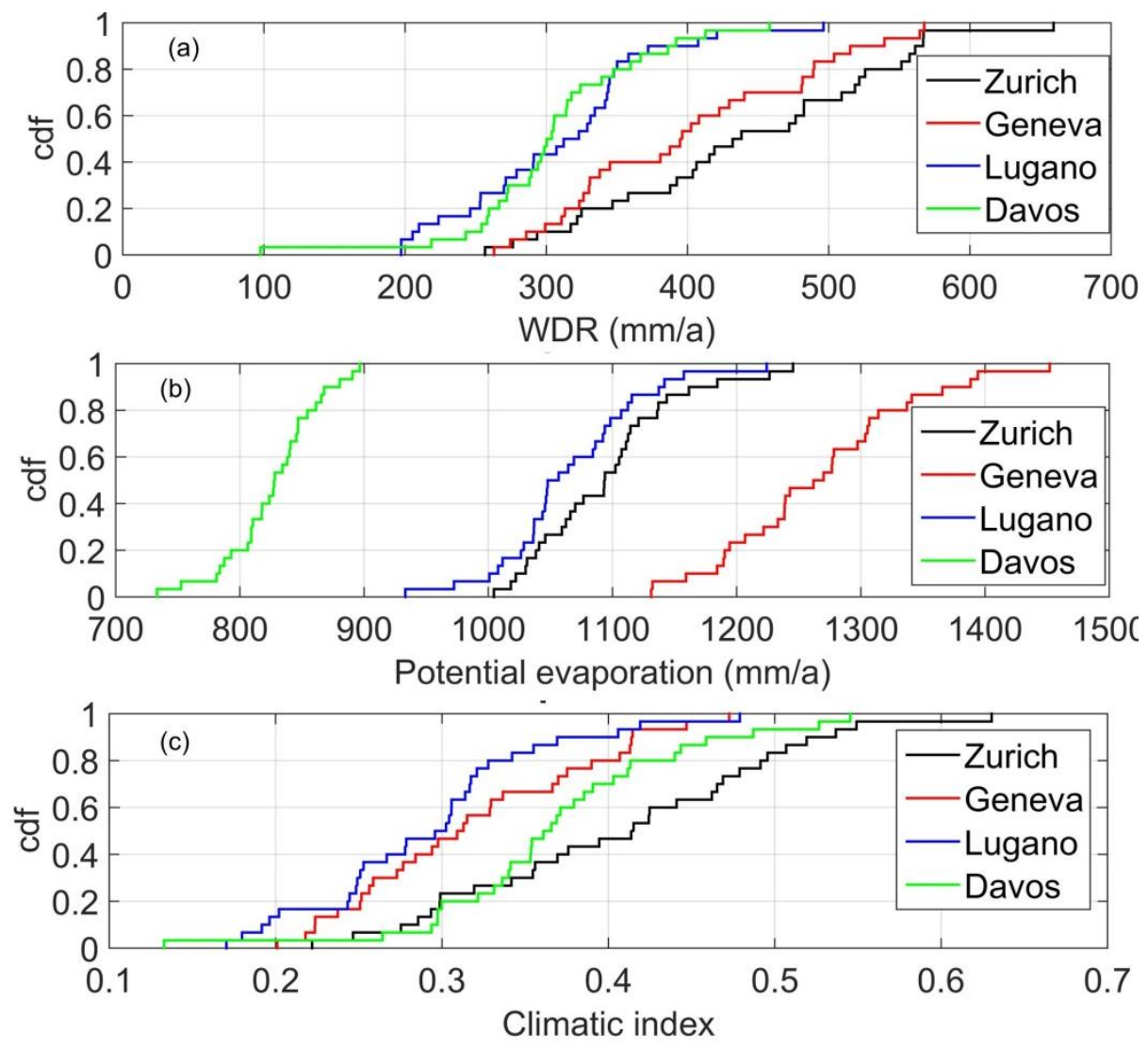

Fig. 5 Cumulative distribution function (cdf) of WDR (a), potential evaporation (b) and Climatic Index (c) for Zurich, Geneva, Lugano and Davos from 1981-2010 at the selected orientations.

Table 1. Statistics of WDR, potential evaporation and Climatic Index for the four cities for years 19812010

\begin{tabular}{|c|c|c|c|c|c|c|c|c|c|c|c|c|}
\hline & \multicolumn{4}{|c|}{ WDR } & \multicolumn{4}{|c|}{ Potential evaporation } & \multicolumn{4}{|c|}{ Climatic Index } \\
\hline & Mean & Min & Max & Std. & Mean & Min & Max & Std. & Mean & Min & Max & Std. \\
\hline Zurich & 441 & 256 & 659 & 101 & 1095 & 1004 & 1245 & 58 & 0.41 & 0.22 & 0.63 & 0.10 \\
\hline Geneva & 401 & 263 & 568 & 90 & 1265 & 1131 & 1452 & 78 & 0.32 & 0.20 & 0.47 & 0.07 \\
\hline Lugano & 308 & 197 & 496 & 69 & 1065 & 933 & 1224 & 58 & 0.29 & 0.17 & 0.48 & 0.07 \\
\hline Davos & 305 & 97 & 458 & 66 & 827 & 733 & 896 & 38 & 0.37 & 0.13 & 0.54 & 0.08 \\
\hline
\end{tabular}

Table 2. Ranking of Climatic Index for the four cities from 1981 to 2010 (wall orientation between brackets).

\begin{tabular}{c|c|c|c|c|c|c|c|c}
\hline \multirow{2}{*}{ Rank } & \multicolumn{2}{|c|}{ Zurich (240 degrees) } & \multicolumn{2}{c|}{ Geneva (240 degrees) } & \multicolumn{2}{c|}{ Lugano (330 degrees) } & \multicolumn{2}{c}{ Davos (30 degrees) } \\
\cline { 2 - 9 } & Year & Climatic Index & Year & Climatic Index & Year & Climatic Index & Year & Climatic Index \\
\hline 1 & 1994 & 0.630 & 1982 & 0.473 & 2000 & 0.479 & 2000 & 0.545 \\
\hline 2 & 1998 & 0.549 & 1994 & 0.447 & 1985 & 0.419 & 1998 & 0.527 \\
\hline 3 & 1993 & 0.537 & 1983 & 0.415 & 1993 & 0.406 & 1986 & 0.487 \\
\hline 4 & 1999 & 0.519 & 2006 & 0.414 & 1987 & 0.369 & 1999 & 0.459 \\
\hline
\end{tabular}




\begin{tabular}{c|c|c|c|c|c|c|c|c}
\hline 5 & 2000 & 0.507 & 2000 & 0.413 & 1982 & 0.355 & 1996 & 0.444 \\
\hline 6 & 1989 & 0.496 & 1998 & 0.407 & 2008 & 0.342 & 1992 & 0.440 \\
\hline 7 & 1981 & 0.491 & 1981 & 0.390 & 1992 & 0.328 & 1991 & 0.413 \\
\hline 8 & 2006 & 0.479 & 1989 & 0.375 & 2001 & 0.321 & 1994 & 0.412 \\
\hline 9 & 2001 & 0.469 & 1993 & 0.370 & 1998 & 0.317 & 2009 & 0.403 \\
\hline 10 & 2003 & 0.465 & 1999 & 0.366 & 2005 & 0.317 & 1983 & 0.391 \\
\hline 11 & 1985 & 0.462 & 2010 & 0.341 & 1997 & 0.314 & 1997 & 0.385 \\
\hline 12 & 2005 & 0.441 & 1987 & 0.337 & 1983 & 0.306 & 1990 & 0.379 \\
\hline 13 & 1997 & 0.425 & 1985 & 0.329 & 1986 & 0.306 & 2010 & 0.371 \\
\hline 14 & 1986 & 0.424 & 2007 & 0.329 & 1984 & 0.304 & 1989 & 0.369 \\
\hline 15 & 2007 & 0.415 & 1997 & 0.315 & 1990 & 0.302 & 2001 & 0.366 \\
\hline 16 & 1987 & 0.414 & 1996 & 0.313 & 1999 & 0.296 & 1984 & 0.361 \\
\hline 17 & 1992 & 0.394 & 2005 & 0.309 & 1981 & 0.279 & 1988 & 0.354 \\
\hline 18 & 1982 & 0.376 & 1986 & 0.298 & 1991 & 0.278 & 1987 & 0.354 \\
\hline 19 & 1983 & 0.369 & 2003 & 0.294 & 1988 & 0.267 & 2006 & 0.353 \\
\hline 20 & 2004 & 0.356 & 1984 & 0.284 & 2010 & 0.253 & 1981 & 0.341 \\
\hline 21 & 1996 & 0.355 & 1992 & 0.277 & 2002 & 0.251 & 1993 & 0.340 \\
\hline 22 & 2002 & 0.342 & 2002 & 0.273 & 2003 & 0.249 & 2003 & 0.336 \\
\hline 23 & 2009 & 0.319 & 1990 & 0.259 & 1994 & 0.248 & 1995 & 0.331 \\
\hline 24 & 1988 & 0.299 & 2001 & 0.256 & 2009 & 0.244 & 2007 & 0.322 \\
\hline 25 & 2008 & 0.299 & 2009 & 0.252 & 2007 & 0.243 & 2004 & 0.300 \\
\hline 26 & 1991 & 0.293 & 1991 & 0.251 & 1996 & 0.202 & 1982 & 0.297 \\
\hline 27 & 1984 & 0.286 & 2008 & 0.237 & 2006 & 0.196 & 2002 & 0.297 \\
\hline 28 & 1990 & 0.275 & 2004 & 0.224 & 1995 & 0.192 & 1985 & 0.294 \\
\hline 29 & 1995 & 0.247 & 1988 & 0.224 & 1989 & 0.180 & 2008 & 0.264 \\
\hline 30 & 2010 & 0.222 & 1995 & 0.218 & 2004 & 0.170 & 2005 & 0.133 \\
\hline
\end{tabular}

For the different years, we also simulate the hygrothermal behavior and evaluate the hygrothermal performance using the RHT Index. We can now compare the Climate Index with the RHT index and evaluate how well the Climate Index can predict the risk for moisture damage. The RHT Index plotted in function of the Climatic Index from 1981 to 2010 is shown in Figs. 6a-c for the three different masonry wall structures. In most cases, the largest Climatic Index corresponds to the largest RHT Index and the smallest Climatic Index corresponds to the smallest RHT Index, indicating a monotonous relation between RHT and Climate Indices. Among the four cities, the correlation coefficients between RHT and Climatic Indices are largest for Geneva. The correlation coefficients between RHT and Climatic Indices are mostly above 0.65 . The correlation coefficients between RHT and Climatic Indices are larger for the internally insulated masonry wall than for the other two types of masonry wall. In the case of masonry wall without insulation, the correlation coefficient between RHT and Climatic Indices for Lugano is 0.62. The explanation for the lower correlation is that the RHT Index of many years in this city is equal to zero, while the Climatic Indices of these instances have determined values. Note that the RHT Index is 0 when the relative humidity at the evaluation location is below the threshold relative humidity of $80 \%$ required for mold growth. Therefore, we can conclude that, within some uncertainty, there is a clear correlation between the RHT and Climatic Indices. 

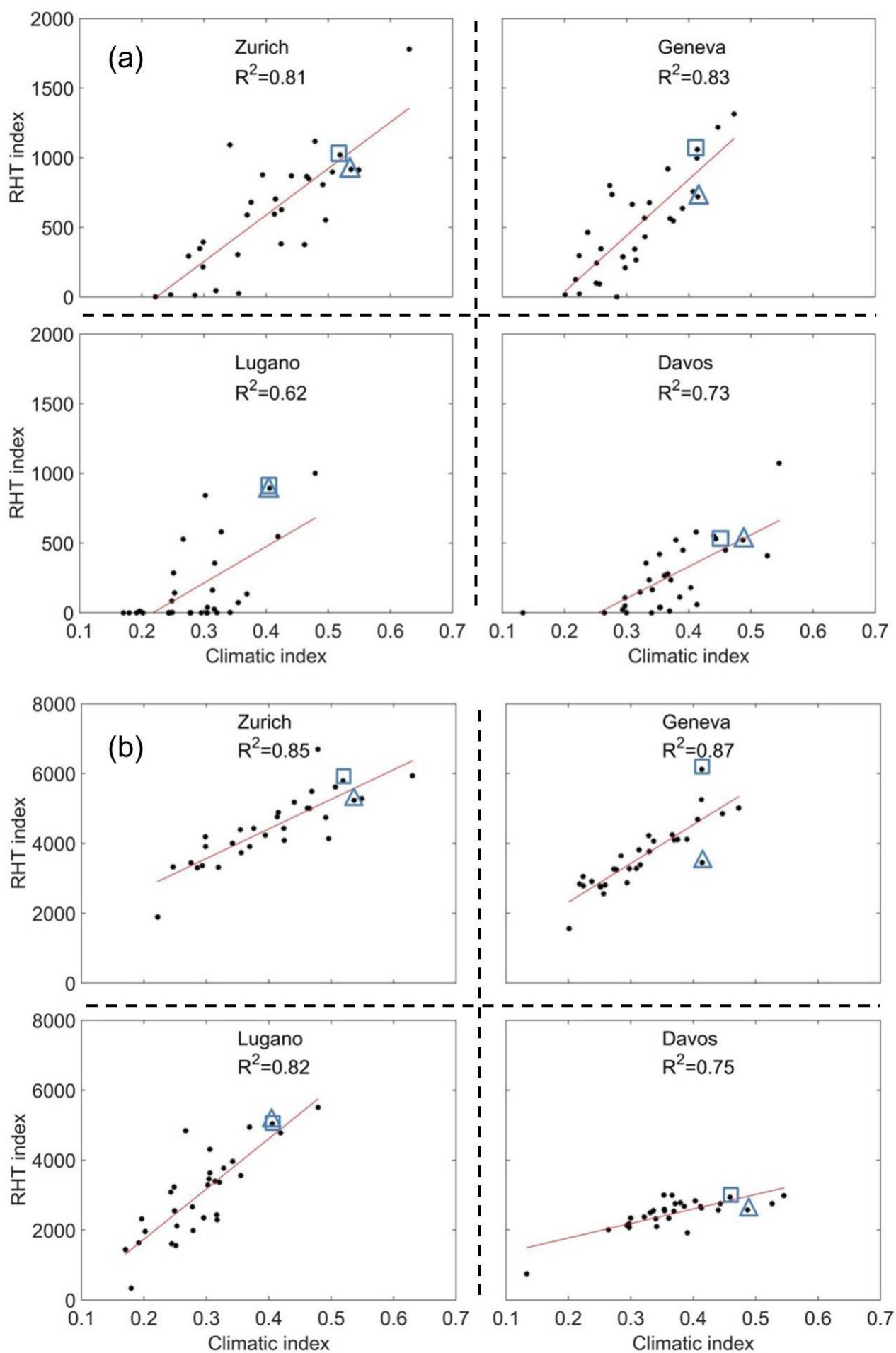

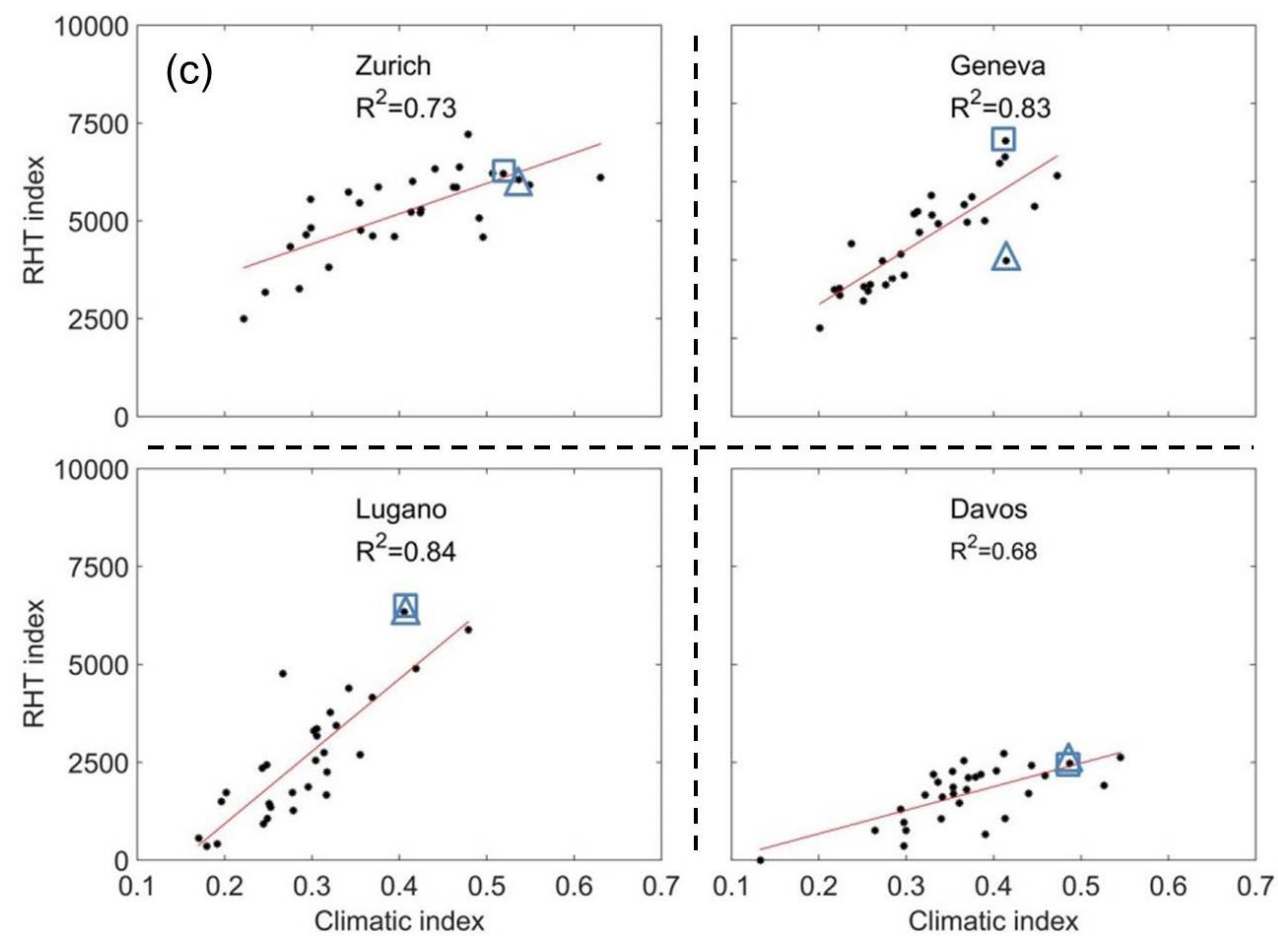

Fig. 6 Relation between RHT Index and Climatic Index for the masonry wall without insulation (a), internally insulated masonry wall (b) and externally insulated masonry wall (c) from 1981 to 2010. The triangles indicate the years with the third largest Climatic index and the squares indicate the chosen moisture reference years based on the new procedure.

For comparison, we also plotted the RHT versus the Moisture Indices for the three masonry wall structures from 1981 to 2010 (Figs. 7a-c). The correlation coefficients between RHT and Moisture Indices are all smaller than those between RHT and Climatic Indices. For instance, the correlation coefficients between RHT and Moisture Indices are 0.69, 0.74, 0.73 and 0.57 in Zurich, Geneva, Lugano and Davos (Fig. 7b), respectively, while the correlation coefficients between the RHT and Climatic Indices are 0.85, $0.87,0.82$ and 0.75 (Fig. 6b), for the internally insulated masonry wall. It is also clear that the data in Fig. 7 is more scattered than in Fig. 6. The reasons for lower correlation coefficients between RHT and Moisture Indices are twofold. First, the drying index in the Moisture Index only partly represents the potential evaporation. The drying index is calculated based on the difference between the humidity ratio at saturation and the humidity ratio in the ambient air. The influence of solar radiation and wind speed on evaporation is not considered. Second, in the determination of Moisture Index, the wetting index and drying index are normalized, as they have different dimensions. After normalization, both the wetting and drying indices range between 0 and 1 . However, the wetting index shows actually relatively much larger variations than the drying index. The variability of the wetting index is reduced due to the normalization. 

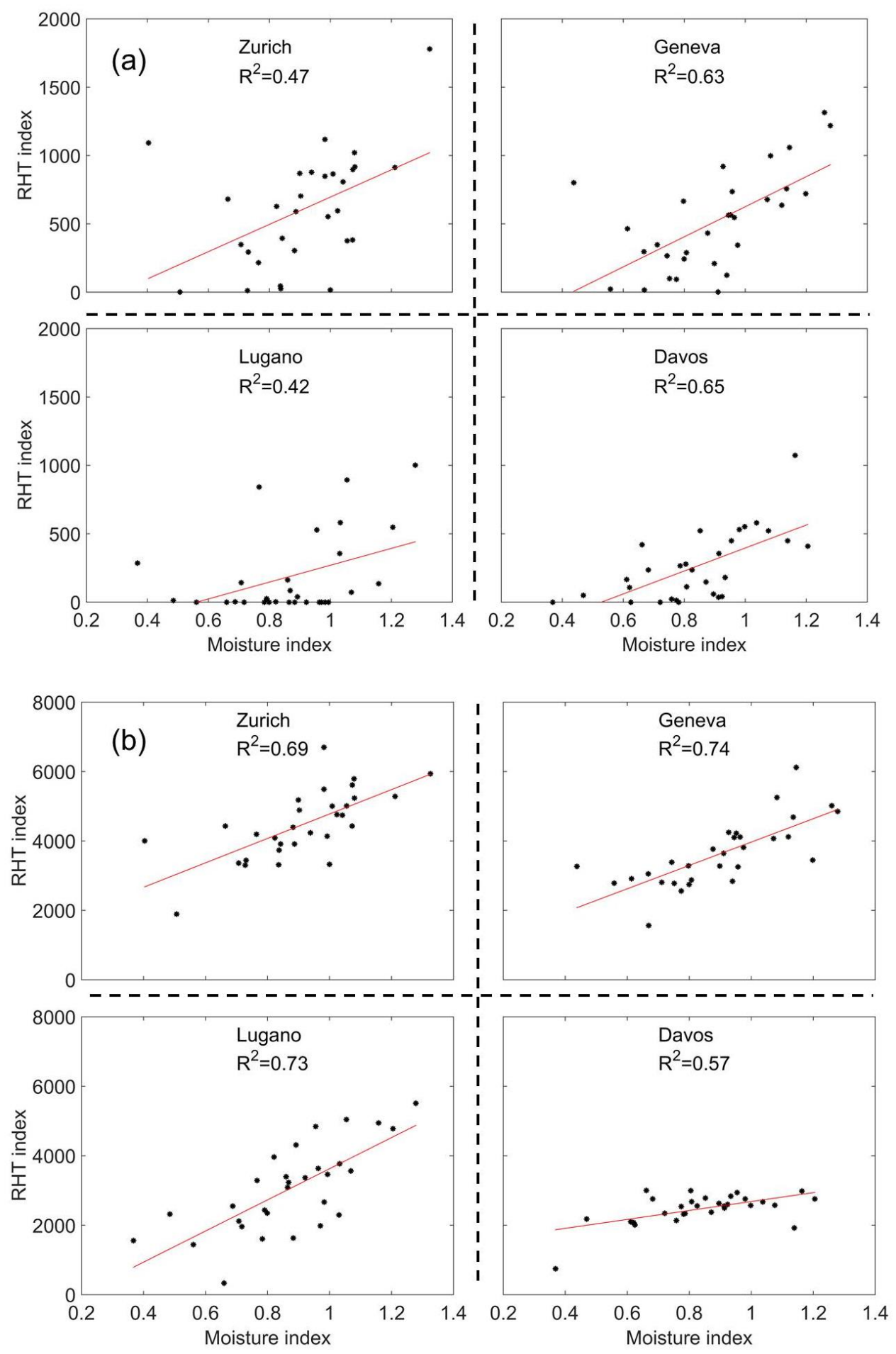


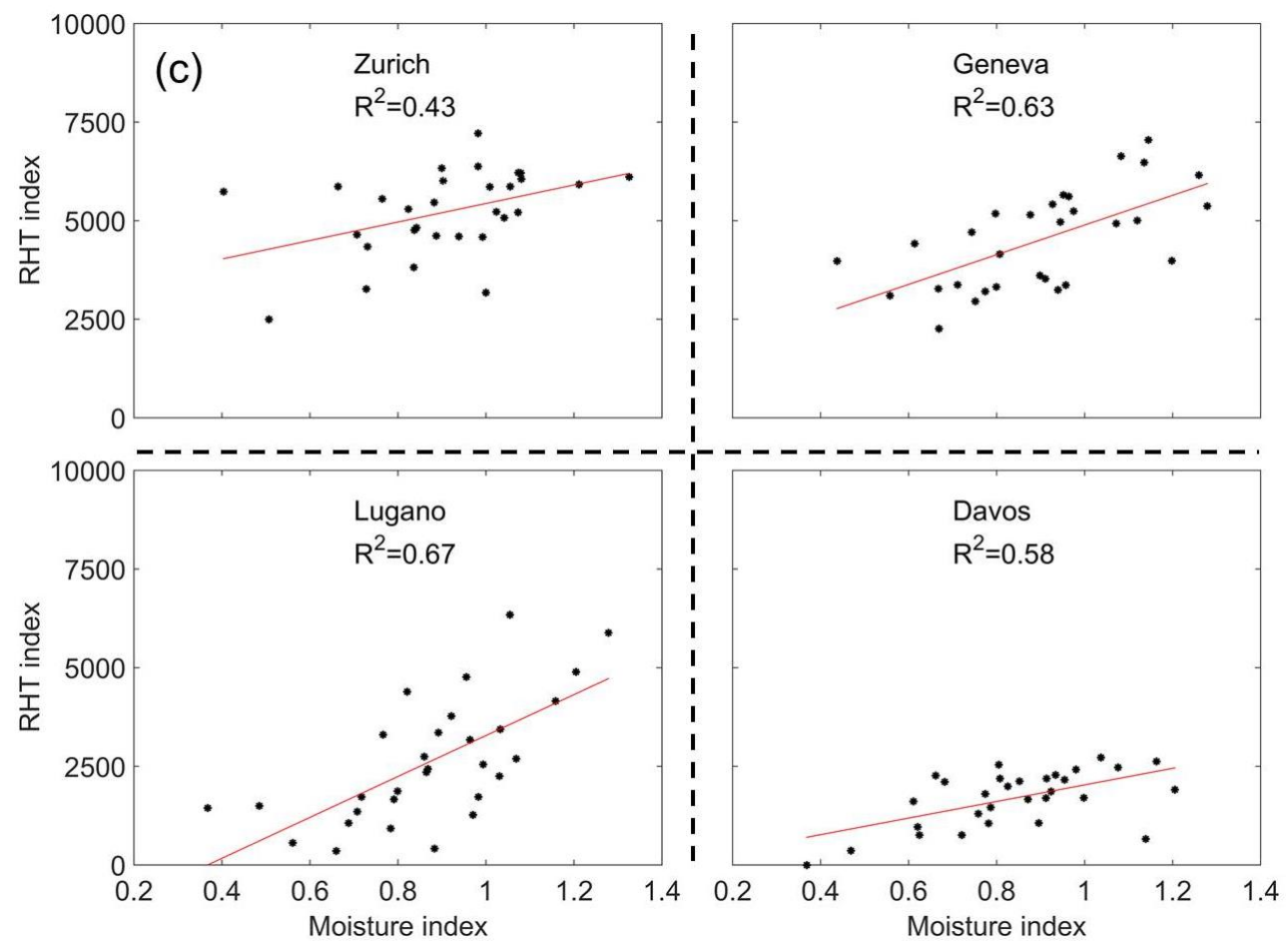

Fig. 7 Relation between RHT index and Moisture Index for the masonry wall without insulation (a), internally insulated masonry wall (b) and externally insulated masonry wall (c) from 1981 to 2010

Fig. 8 presents the RHT versus Climate Indices for the internally insulated wall assemblies for Zurich, Geneva and Lugano. The Climatic Index for this wall in Zurich shows the largest values while the ones in Lugano are the smallest. There is a strong correlation of 0.84 between the RHT and Climatic Indices, although the three cases considered are for different climates and orientation. It indicates that the Climatic Index can be used as indicator for moisture problems, to compare the risks of moisture problems among different regions. The advantage of the Climatic Index is that it can be easily determined for each wall orientation and, consequently, the moisture risk per orientation can be quantitatively evaluated. 


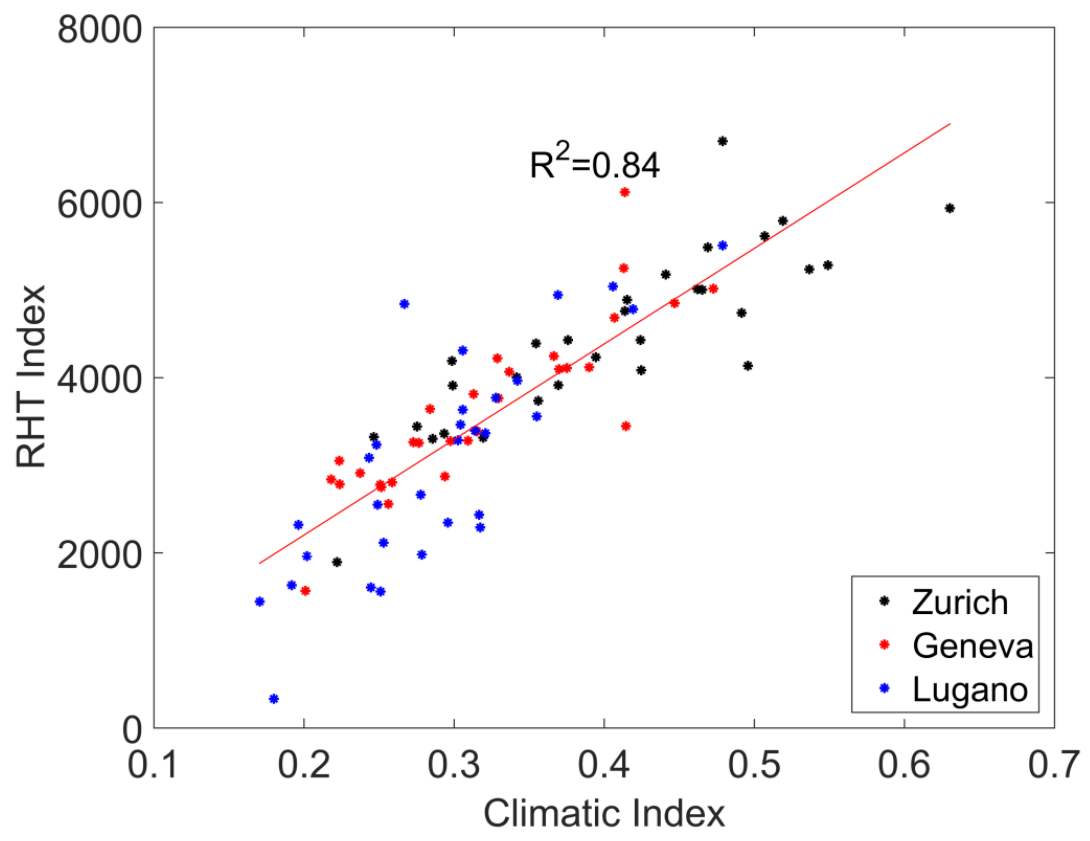

Fig. 8 Relation between RHT Index and Climatic Index for Zurich, Geneva and Lugano for the internally insulated masonry wall from 1981 to 2010.

\section{New procedure for selecting a moisture reference year}

The common procedure for selecting a moisture reference year aims at finding that year that shows a $10 \%$ failure level, or a $90 \%$ safety level. For a 30 -year dataset, this $10 \%$-level year corresponds to the third wettest year. Using the Climate Index as moisture damage indicator, these years are the years from table 2 with the third largest Climatic Index: 1993, 1983, 1993 and 1986 for Zurich, Geneva, Lugano and Davos, respectively. In order to evaluate whether these years are indeed 10\%-level moisture risk years, the RHT Index of these years is analyzed. In Figs. 6a-c the RHT Indices for the selected years are indicated with a triangle. We observe that the RHT Indices of the selected years do not represent the third largest RHT values, meaning they are not the third wettest years. Especially for Geneva, the RHT Index for 1983 is found to be relatively smaller than the third value (the triangle is actually situated below the correlation line). When comparing the RHT values for the years showing the fourth (2006) and fifth (2000) largest Climate Index, these RHT values are found to be higher for all wall types, meaning they are probably more representative of a moisture reference year. This means that the selection of the moisture reference year based on the third largest Climate Index does not guarantee the selection of a proper moisture reference year.

This observation is analyzed in more detail for the internally insulated masonry wall in Geneva. It is remarked that the observations are similar for the other two types of masonry walls. The analysis is based on a comparison of three years showing third, fourth and fifth ranking in Climatic Index. For Geneva, these years are 1983 (third), 2000 (fifth) and 2006 (fourth). Fig. 9b shows the RHT index summed over time for these three years. Year 1983 shows smaller values than those for year 2000 and 2006, starting from the beginning until the end of the year. There are two reasons for the smaller RHT values in 1983. The first reason is a temperature effect. Fig. 9c shows the daily wall temperature summed over time, as assessed in the evaluation region. It is clear that the temperature is lower in 1983 compared to the two other years. This lower wall temperature is due to the lower air temperatures in 1983, as shown in Fig. 9f, where the cumulative daily air temperature clearly indicates that the air temperature in 1983 is lower than that of the other two years. According to the selected moisture damage criterion, lower wall temperatures 
indicate a lower sensitivity to moisture damage: a smaller difference between wall and threshold temperature for moisture damage leads indeed to smaller RHT values. The second reason is related to the distribution of WDR over time. Although the WDR load in $1983\left(515 \mathrm{mma}^{-1}\right)$ is close to the values for the other two years, its distribution over time is quite different. Fig. 9d gives the cumulative WDR amount over time for the three years. In 1983, large amounts of WDR occur in short time periods, i.e. at the end of November and at the beginning of February, while the WDR amount is low for other periods, such as from June to August 1983 (only $33 \mathrm{~mm}$ ). The low WDR amount in this period leads to a more substantial drying of the masonry wall and, as a result, to lower relative humidity values in the masonry wall. Fig. 9a shows the variation of RH over time in the evaluation region, showing much lower values from July on for 1983. Since the RHT value depends directly on the difference between wall and threshold RH for moisture damage, lower RH values result in a lower slope in the cumulative RHT curve over this period (dashed lines in Fig. 9b) and in lower RHT values for 1983 compared to the values in the other two years. In conclusion, the level of mean air temperature and the alternation of wet and dry periods with respect to WDR for certain years may make that the Climate Index is not sufficient to select a proper moisture reference year.
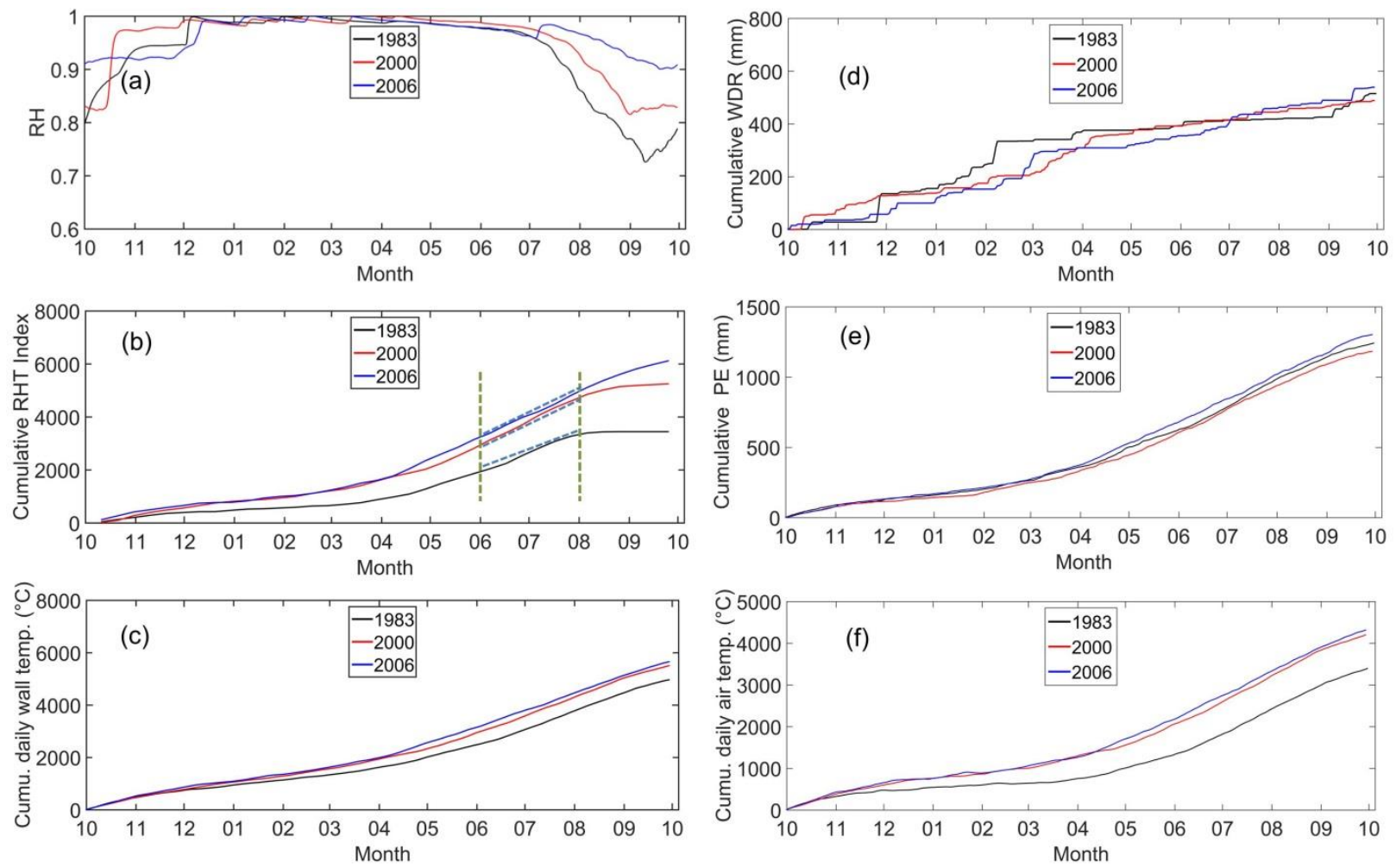

Fig. 9 Variation of relative humidity (a), cumulative RHT Index (b), cumulative daily wall temperature in the selected region (c), cumulative WDR (d), potential evaporation (e) and cumulative daily air temperature (f) for the internally insulated masonry wall for the year 1983, 2000 and 2006 for Geneva 
In the above, it was shown that the 10\%-level year selected on the Climatic Index for Geneva does not show a corresponding 10\%-level moisture risk, since the Climatic Index only considers wetting and drying potentials and not the real hygrothermal response as given by the hygrothermal simulations and corresponding RHT index. It is also remarked that the hygrothermal performance indicator, the RHT Index, represents the combined effect of moisture and temperature for a certain wall and, as such, is influenced by the material properties, while the Climatic Index does not consider a specific wall. Even though the total WDR amount can be similar, a different distribution of WDR over time can lead to very different wetting behavior of the building envelope affecting the moisture accumulation in the building envelope. Selecting an inappropriate moisture reference year based on the $10 \%$ level Climatic Index criterion can therefore be precarious, as it may lead to an unsafe evaluation of the moisture durability of building envelope.

The uncertainty in selecting the appropriate moisture reference year based on a 10\% level Climate Index criterion therefore necessitates a new approach. We propose the following procedure: first select a set of years around the 10\%-level Climatic Index; perform hygrothermal simulations for these years and determine the RHT values; select out of this set of years the year with the highest RHT value. More specific for our case of a weather dataset of 30-year, we propose to determine the RHT Indices for the years with the third, fourth and fifth largest Climatic Indices, and then select the year with the largest RHT Index among these three years as moisture reference year. The results of this procedure is exemplified in Fig. 6, where the squares indicate the RHT of the selected moisture reference years obtained following the new procedure. These years (squares) show for some walls and cities a RHT index close to the values obtained from the common method (triangles), while for others the RHT index is higher, indicating a more reliable determination using the new procedure. This means that the new procedure helps to reduce the uncertainty in selecting a proper moisture reference year. Fig. 10 compares the RHT Indices of the moisture reference years selected based on the 10\% level Climate Index and the new procedure. For most locations, different years are selected as moisture reference year. The final moisture damage risk percentages of the selected moisture reference years are determined based on their ranking in RHT index. The moisture damage risks are shown in Table 3. The moisture damage risk percentages range between $3.3 \%$ and $13.3 \%$ around the $10 \%$ damage risk. Therefore, we may conclude that the proposed method provides reliable prediction of the moisture damage risk percentages below a $10 \%$.

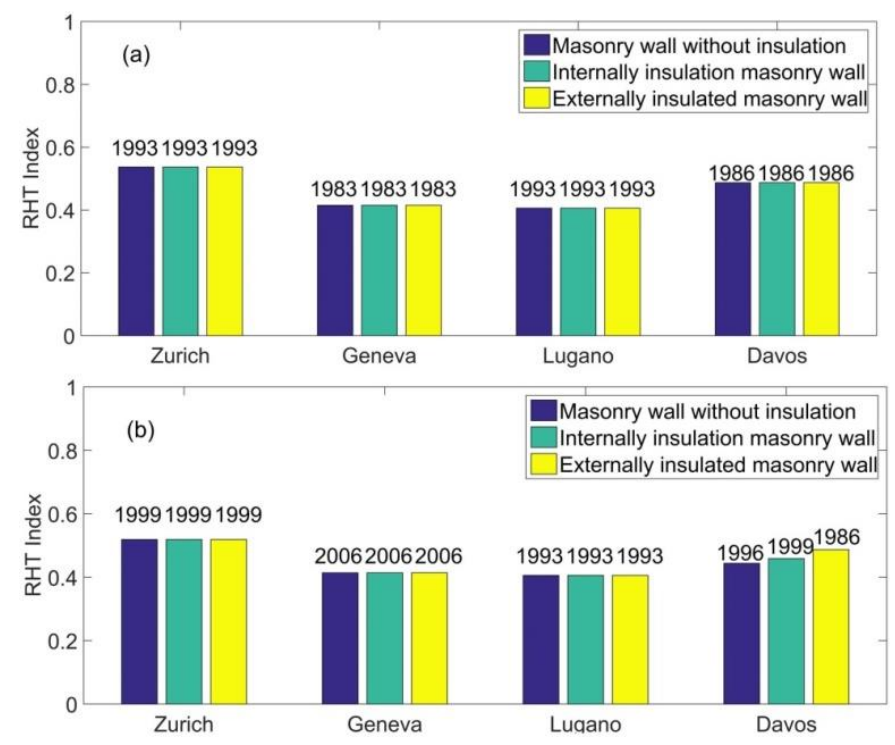

Fig. 10 (a) Selected moisture reference year based on 10\% level criteria; (b) Selected moisture reference year based on the new procedure. 
Comparing the moisture reference years for different walls, the selected moisture reference years are found to be the same years for Zurich, Geneva and Lugano. In contrast, for Davos, the selected moisture reference years are different for each wall type. This dependence of moisture reference year on wall type may be explained by the fact that the RHT Index highly depends on the wall temperature in the evaluation region. For Davos, the mean annual air temperature is $3.9^{\circ} \mathrm{C}$, resulting in low wall temperatures, lower than the mold growth threshold temperature of $5{ }^{\circ} \mathrm{C}$. This means that, for Davos, the RHT will be often zero. We remark that the newly proposed method properly takes into account temperature effects. We may conclude that the combined use of RHT and Climatic Indices as proposed in the new procedure is a useful way to select a representative moisture reference year in a reliable manner.

Table 3. Level of moisture damage risk of the selected years as determined by RHT Index

\begin{tabular}{c|c|c|c|c}
\hline & Zurich & Geneva & Lugano & Davos \\
\hline Masonry wall without insulation & $13.3 \%$ & $10.0 \%$ & $6.7 \%$ & $13.3 \%$ \\
\hline Internally insulated masonry wall & $10.0 \%$ & $3.3 \%$ & $6.7 \%$ & $13.3 \%$ \\
\hline Externally insulated masonry wall & $13.3 \%$ & $3.3 \%$ & $3.3 \%$ & $13.3 \%$ \\
\hline
\end{tabular}

In this study, we proposed to select the wall orientation with the largest Climatic Index for the determination of the moisture reference year. In reality, the orientation of the façade under study may be different from this orientation. As an example, Fig. 11 shows the RHT versus Climate Indices for the internally insulated wall assemblies for three different façade orientations for Zurich. In general, a larger Climatic Index corresponds to a larger RHT index, showing a linear relation with a correlation coefficient of 0.84. However, a year with a high ranking at one façade orientation does not necessarily relates to a year with the same ranking at the other façade orientations (Table 4). For example, the RHT Index in the year of 1999 ranks $3^{\text {rd }}$ when the façade orientation is 240 degrees, whereas the RHT Index in this year ranks $7^{\text {th }}$ and $8^{\text {th }}$ when the façade orientation is 180 and 300 degrees. However, the selection of moisture reference year based on the orientation with the largest Climatic Index is found to be a conservative choice with respect to the other orientations. The RHT Index value reaches 5789 at the façade orientation of 240 degrees (the orientation with the largest Climatic Index) for the selected moisture reference year 1999, while the largest RHT Index value at the façade orientation of 180 and 300 degrees is 4123 and 5109 , respectively (Table 4). 


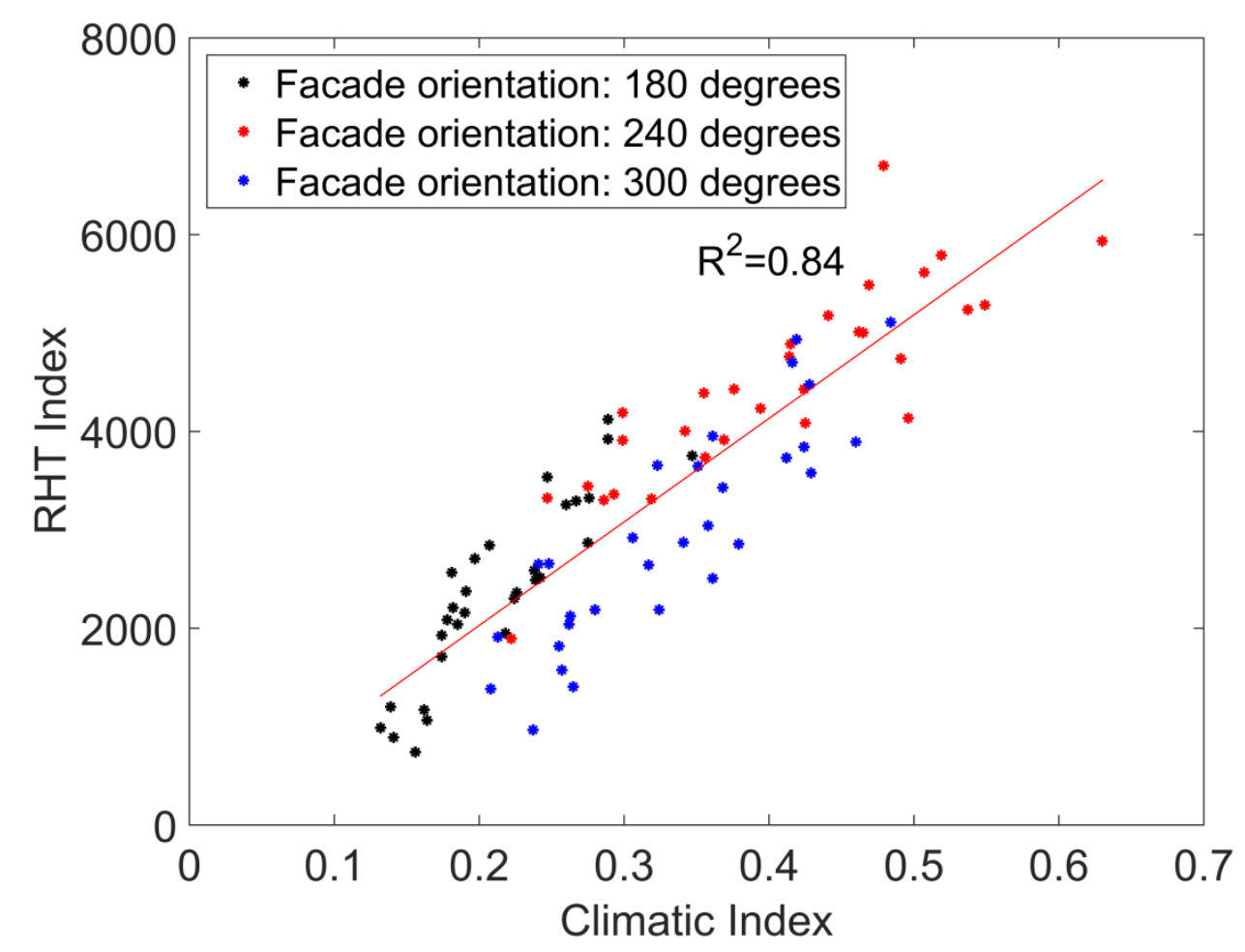

Fig. 11. Relation between RHT Index and Climatic Index for 3 façade orientations for the internally insulated masonry wall from 1981 to 2010.

Table 4. Top ten RHT Indices for the three façade orientations

\begin{tabular}{c|c|c|c|c|c|c|c|c|c}
\hline \multirow{2}{*}{ Rank } & \multicolumn{3}{|c|}{ Zurich (180 degrees) } & \multicolumn{3}{c|}{ Zurich (240 degrees) } & \multicolumn{4}{c}{ Zurich (300 degrees) } \\
\cline { 2 - 10 } & Year & $\begin{array}{c}\text { RHT } \\
\text { Index }\end{array}$ & $\begin{array}{c}\text { Climatic } \\
\text { Index }\end{array}$ & Year & $\begin{array}{c}\text { RHT } \\
\text { Index }\end{array}$ & $\begin{array}{c}\text { Climatic } \\
\text { Index }\end{array}$ & Year & RHT Index & $\begin{array}{c}\text { Climatic } \\
\text { Index }\end{array}$ \\
\hline 1 & 2000 & 4123 & 0.289 & 2006 & 6700 & 0.479 & 1994 & 5109 & 0.484 \\
\hline 2 & 1998 & 3924 & 0.289 & 1994 & 5935 & 0.630 & 2001 & 4936 & 0.419 \\
\hline 3 & 1994 & 3752 & 0.347 & 1999 & 5789 & 0.519 & 2006 & 4702 & 0.416 \\
\hline 4 & 1985 & 3535 & 0.247 & 2000 & 5615 & 0.507 & 2000 & 4476 & 0.428 \\
\hline 5 & 1993 & 3323 & 0.276 & 2001 & 5488 & 0.469 & 2007 & 3952 & 0.361 \\
\hline 6 & 2005 & 3291 & 0.267 & 1998 & 5285 & 0.549 & 1989 & 3895 & 0.460 \\
\hline 7 & 1999 & 3256 & 0.260 & 1993 & 5237 & 0.537 & 2003 & 3843 & 0.424 \\
\hline 8 & 1981 & 2868 & 0.275 & 2005 & 5178 & 0.441 & 1999 & 3730 & 0.412 \\
\hline 9 & 1987 & 2843 & 0.207 & 1985 & 5010 & 0.462 & 2005 & 3657 & 0.323 \\
\hline 10 & 2003 & 2707 & 0.197 & 2003 & 5005 & 0.465 & 1987 & 3646 & 0.351 \\
\hline
\end{tabular}




\section{Conclusions}

A new index, called the Climatic Index, is proposed to evaluate the severity to which building envelopes are exposed to a certain outside climate considering both the wetting load and evaporation potential for a typical climate region. The Climate Index evaluates the balance between wetting and drying potentials and is used for the selection of a moisture reference year. For this analysis, three types of masonry wall assemblies (masonry wall without insulation, internally insulated masonry wall and externally insulated masonry walls) for four cities in Switzerland were simulated in detail with a state-of-the-art heat and mass model. Based on these simulations, the RHT Index was determined for hygrothermal performance assessment. A clear correlation between Climatic Index and the hygrothermal performance indicator RHT Index is found, showing that the Climatic Index can be retained for the assessment of moisture damage risks. The analysis demonstrates that the selection of moisture reference year based on $10 \%$ level criterion of Climatic Index however may lack robustness for all cities and wall types. It was found that the influence of mean air temperature, of the distribution of WDR and of the material properties of the wall under consideration are not well captured by the Climatic Index and, as such, may lead to a selection of less severe moisture reference years than aimed at by a $10 \%$ risk level. Therefore, a new procedure is proposed which combines a first selection of three years around the $10 \%$ level criterion, followed by a careful comparison of these years based on hygrothermal simulations and the selection of the year with the largest RHT Index as moisture reference year. The combination of Climatic Index and RHT Index from hygrothermal simulations allows for the selection of moisture reference years that are around the $10 \%$ level, but excluding the ambiguity on the selection of a proper moisture reference year for low extra computational cost. We believe that this improved selection of moisture reference years will lead to more reliable evaluation of moisture damage risks and, in the long run, better designed building envelopes with respect to moisture damage.

\section{Acknowledgement}

The support of SCCER FEEB\&D (future Energy Efficient Buildings \& Districts) is acknowledged.

\section{Reference}

[1] Lstiburek J. Moisture control for buildings. Ashrae J. 2002;44:36-41.

[2] Glaser H. Wärmeleitung und Feuchtigkeitsdurchgang durch Kühlraumisolierungen. Kältetechnik. 1958;10:86-91.

[3] Ashrae AH. Fundamentals. American Society of Heating, Refrigerating and Air-Conditioning Engineers, Atlanta. 2001.

[4] Delgado JM, Barreira E, Ramos NM, De Freitas VP. Hygrothermal numerical simulation tools applied to building physics: Springer Science \& Business Media; 2012.

[5] Kalamees T, Vinha J. Estonian climate analysis for selecting moisture reference years for hygrothermal calculations. J Therm Envel Build Sci. 2004;27:199-220.

[6] Kalamees T, Jylha K, Tietavainen H, Jokisalo J, Ilomets S, Hyvonen R, et al. Development of weighting factors for climate variables for selecting the energy reference year according to the EN ISO 15927-4 standard. Energ Buildings. 2012;47:53-60.

[7] Bilbao J, Miguel A, Franco JA, Ayuso A. Test reference year generation and evaluation methods in the continental Mediterranean area. J Appl Meteorol. 2004;43:390-400.

[8] Pernigotto G, Prada A, Costola D, Gasparella A, Hensen JLM. Multi-year and reference year weather data for building energy labelling in north Italy climates. Energ Buildings. 2014;72:6272. 
[9] Sanders C. Heat, air and moisture transfer in insulated envelope parts: Environmental conditions. International Energy Agency, Annex 24 Final report,volume 2 Acco, Leuven; 1996. 1996;24.

[10] Ali Mohamed F, Hens H. Outdoor climate: reference year. Equivalent temperature for condensation. International Energy Agency. Energy Conservation in Buildings and Community Systems, Annex 24 Heat-Air and Moisture Transfer in Insulated Envelope Parts (HAMTIE). Report T2-B-92/03; 1992.

[11] Geving S. Moisture design of building constructions: Hygrothermal analysis using simulation models-Part I and II [PhD thesis]. Norwegian University of Science and Technology;1997.

[12] Hagentoft $C$, Harderup E. Climatic influences on the building envelope using the $\Pi$ factor. IEA-Annex 24 Hamtie Task 2: Environmental Conditions. Closing seminar, Finland; 1996.

[13] Cornick S, Djebbar R, Dalgliesh WA. Selecting moisture reference years using a Moisture Index approach. Build Environ. 2003;38:1367-79.

[14] Hens HS. Applied building physics: boundary conditions, building performance and material properties: John Wiley \& Sons; 2010.

[15] Hillel D. Introduction to environmental soil physics: Academic press; 2003.

[16] Salonvaara M, Sedlbauer K, Holm A, Pazera M. Effect of selected weather year for hygrothermal analyses. In: Proceedings of thermal performance of the exterior envelopes of whole buildings XI Atlanta: American Society of Heating, Refrigerating and Air-Conditioning Engineers, Inc;2010.

[17] Mukhopadhyaya P, Kumaran K, Tariku F, van Reenen D. Application of hygrothermal modeling tool to assess moisture response of exterior walls. J Arch Eng. 2006;12:178-86.

[18] Kubilay A, Derome D, Blocken B, Carmeliet J. High-resolution field measurements of winddriven rain on an array of low-rise cubic buildings. Build Environ. 2014;78:1-13.

[19] Kubilay A, Derome D, Blocken B, Carmeliet J. CFD simulation and validation of winddriven rain on a building facade with an Eulerian multiphase model. Build Environ. 2013;61:6981.

[20] TenWolde A. ASHRAE Standard 160 P-Criteria for Moisture Control Design Analysis in Buildings. ASHRAE Transactions. 2008;114:167-71.

[21] Jensen DT, Hargreaves GH, Temesgen B, Allen RG. Computation of ETo under nonideal conditions. J Irrig Drain E-Asce. 1997;123:394-400.

[22] Penman HL. Natural evaporation from open water, bare soil and grass. Proceedings of the Royal Society of London A: Mathematical, Physical and Engineering Sciences: The Royal Society; 1948. p. 120-45.

[23] Priestley C, Taylor R. On the assessment of surface heat flux and evaporation using largescale parameters. Mon Weather Rev. 1972;100:81-92.

[24] Blaney HF. Determining water requirements in irrigated areas from climatological and irrigation data. USDA Soil Conservation Service Tech Paper 96; 1952.

[25] Janssen H, Blocken B, Carmeliet J. Conservative modelling of the moisture and heat transfer in building components under atmospheric excitation. Int J Heat Mass Tran. 2007;50:1128-40.

[26] Hagentoft C-E, Kalagasidis AS, Adl-Zarrabi B, Roels S, Carmeliet J, Hens H, et al. Assessment method of numerical prediction models for combined heat, air and moisture transfer in building components: benchmarks for one-dimensional cases. J Therm Envel Build Sci. 2004;27:327-52.

[27] Künzel HM. Simultaneous heat and moisture transport in building components. 1995. 
[28] Guizzardi M, Derome D, Vonbank R, Carmeliet J. Hygrothermal behavior of a massive wall with interior insulation during wetting. Build Environ. 2015;89:59-71.

[29] EN-15026. Hygrothermal performance of building components and building elements Assessment of moisture transfer by numerical simulation. 2007.

[30] Iqbal M. An introduction to solar radiation: Elsevier; 2012.

[31] Kumaran M, Lackey J, Normandin N, van Reenen D, Tariku F. Summary report from task 3 of MEWS project at the Institute for Research in Construction-Hygrothermal properties of several building materials. National Research Council, Ottawa, Canada; 2002.

[32] Garverick L. Corrosion in the petrochemical industry: ASM international; 1994.

[33] Viitanen H, Toratti T, Makkonen L, Peuhkuri R, Ojanen T, Ruokolainen L, et al. Towards modelling of decay risk of wooden materials. Eur J Wood Wood Prod. 2010;68:303-13. 